Musa Bashorov ${ }^{1}$, Georgiy Kozlov ${ }^{1}$, Gennady Zaikov ${ }^{2}$ and Abdulakh Mikitaev ${ }^{1}$

\title{
POLYMERS AS NATURAL NANOCOMPOSITES. 3. THE GEOMETRY OF INTERCOMPONENT INTERACTIONS
}

\author{
${ }^{1}$ Kabardino-Balkarian State University, 173 Chernyshevskiy str., $360004 \mathrm{Nal}$ 'chik, Russia \\ ${ }^{2}$ N.M. Emanuel Institute of Biochemical Physics of Russian Academy of Sciences, \\ 4 Kosygin str., 119334 M oscow, Russia
}

Received: N ovember 18, 2008

(C) Bashorov M., Kozlov G., Zaikov G., Mikitaev A., 2009

\begin{abstract}
The treatment of amorphous glassy polymers as natural nanocomposites is proposed. It has been shown that the geometry of intercomponent interactions nanoclusters - loosely-packed matrix defines adhesion level between the indicated components of natural nanocomposites. Since nanoclusters - loosely-packed matrix contact is realized over cylindrical surface of the first ones then the larger the indicated surface area the higher the intercomponent adhesion level.
\end{abstract}

Keywords: amorphous polymer, nanocomposite, adhesion, structure, reinforcement.

\section{Introduction}

At present it becomes obvious that polymeric systems in virtue of their structure features are always nanostructural systems [1]. However, such structure treatment can be various. Some of the authors [2] have used for this purpose the cluster model of polymers amorphous state structure, which assumes that the mentioned structure consists of local order domains (clusters) immersed in loosely-packed matrix. In this case the latter is considered as a natural nanocomposite matrix and clusters - as a nanofiller. A cluster is a set of several densely-packed collinear segments of different macromolecules with the size up to several nanometers [3]. It has been shown that such clusters are true nanoparticles - the nanoworld objects (nanoclusters) [2].

In such polymers structure treatment the interactions between structural components nanoclusters and loosely-packed matrix (intercomponent interactions) becomes of paramount importance. As it is known [8], in multiphase (multicomponent) systems such interactions exercise the defining influence on the indicated systems properties. Therefore the purpose of the present paper is the study of intercomponent interactions' type and level as well as the way they are influenced by nanoclusters geometry on the example of typical amorphous glassy polymer - polycarbonate.

\section{Experimental}

Polycarbonate (PC) on the basis of bisphenol A with molecular weight $\sim 5 \cdot 10^{4}$ was used. PC films of thickness $\sim 0.1 \mathrm{~mm}$ were prepared by pouring of $5 \%$ polymer solution in methylene chloride on cellophane substrate and their subsequent drying in vacuum at $393 \mathrm{~K}$ during 2 days for complete removal of moisture and solvent. "Dogbone" shaped samples for mechanical testing with basic length of $40 \mathrm{~mm}$ and working width of $5 \mathrm{~mm}$ were cut out from these films using a templet. Uniaxial tension was tested on the Instron testing machine at strain rate $\sim 10^{-3} \mathrm{~s}^{-1}$ within the temperature limits $293-413 \mathrm{~K}$. Before testing the samples were kept in thermal chamber of the testing machine during $15 \mathrm{~min}$ to achieve thermal equilibrium. Each data point was obtained according to 5 five test results of the samples.

\section{Results and Discussion}

The authors [5] considered three main cases of reinforcement degree $E_{c} / E_{m}$ (where $E_{c}$ and $E_{m}$ are elasticity module of composite and matrix polymer, respectively) dependence on filler volume contents $\varphi_{f}$ They showed that the following main types of the dependences $E_{c} E_{m}(\varphi)$ existed:

1) the ideal adhesion between filler and polymer matrix described by Kerner equation, which can be approximated by the following relationship:

$$
\frac{E_{c}}{E_{m}}=1+11.6 \varphi_{f}-44.4 \varphi_{f}^{2}+96.3 \varphi_{f}^{3}
$$

2) zero adhesional strength at a large friction coefficient between filler and polymer matrix, which is described by the equation:

$$
\frac{E_{c}}{E_{m}}=1+\varphi_{f}
$$

3) the complete absence of interaction and the ideal slip between filler and polymer matrix, when composite 
elasticity modulus is practically defined by polymer crosssection and connected with the filling degree by the equation:

$$
\frac{E_{c}}{E_{m}}=1-\varphi_{f}^{2 / 3}
$$

It is obvious that in model [5] which is used for the natural nanocomposites behaviour description the following choice should be accepted: $E_{c}=E_{p}, E_{m}=E_{l m}$ and $\varphi_{f}=\varphi_{c p}$ where $E_{p}$ and $E_{l m .}$ are elasticity module of polymer and looselypacked matrix, respectively, and $\varphi_{c l}$ is a relative fraction of nanoclusters (nanofiller). For the $\varphi_{c l}$ value estimation the following percolation relationship was used [6]:

$$
\varphi_{c l}=0.03\left(T_{g}-T\right)^{0.55}
$$

where $T_{g}$ and $T$ are glass transition and testing temperatures, respectively. For PC $T_{g}=423 \mathrm{~K}$ [7].

For the $E_{l . m}$ value estimation the graphic method was selected. For this purpose the dependence $E_{p}\left(\varphi_{c l}\right)$ was plotted and turned out to be linear and breaking up into two parts at border temperature $373 \mathrm{~K}$. Then by extrapolation of the indicated linear parts to $\varphi_{c}=0$ the values $E_{l m}$ were determined: $0.85 \mathrm{GPa}$ for the range $293-363 \mathrm{~K}$ and $0.38 \mathrm{GPa}$ for the range $373-413 \mathrm{~K}$. In Fig. 1 the theoretical dependences $E_{p} / E_{l m}\left(\varphi_{c}\right)$ plotted according to the equations (1)-(3) as well as experimental data for PC (points) are shown. As follows from the comparison shown in Fig. 1 at $T=293-363 \mathrm{~K}$ the experimental data correspond well to the Eq. (2), i.e. in this case zero adhesion strength at a large friction coefficient is observed. At $T=$ $373-413 \mathrm{~K}$ the experimental data correspond well to the Eq. (1), i.e. the ideal adhesion between nanoclusters and loosely-packed matrix is observed. Therefore, the data adduced in Fig. 1 demonstrate that depending on testing temperature two types of nanoclusters - loosely-packed matrix interaction are observed: either an ideal adhesion or a large friction between them. For quantitative estimation of these interactions let's estimate first of all their level, which can be done with the aid of the parameter $b$, determined according to the equation [8]:

$$
\sigma_{f}^{c}=\sigma_{f}^{m} K_{c}-b \varphi_{f}
$$

where $\sigma_{f}^{c}$ and $\sigma_{f}^{m}$ are fracture stress of composite and polymer matrix, respectively, and $K_{c}$ is stress concentration coefficient. It is obvious that since $b$ increase results to $\sigma_{f}^{c}$ reduction, then this means the interfacial adhesion level reduction.

As $\sigma_{f}^{c}$ for natural nanocomposites the true fracture stress $\sigma_{f}^{t r}$ was used, which takes into account sample cross-section change in deformation process, which can be determined according to the known formula:

$$
\sigma_{f}^{t r}=\sigma_{f}^{n}\left(1+\varepsilon_{f}\right)
$$

where $\sigma_{f}^{n}$ is a nominal (technical) fracture stress, $\varepsilon_{f}$ is fracture strain.

The value $\sigma_{f}^{m}$, which is accepted equal to looselypacked matrix strength $\sigma_{f}^{l . m .}$, was determined by graphic, namely, by plotting graph $\sigma_{f}^{t r}\left(\varphi_{c}\right)$, which turns out to be linear, and its subsequent extrapolation to $\varphi_{c l}=0$, that gives $\sigma_{f}^{l . m .}=40 \mathrm{MPa}$.

And lastly, the value $K_{c}$ can be determined with the aid of the following equation [9]:

$$
\sigma_{f}^{t r}=\sigma_{f}^{l . m .}\left(1-\varphi_{c l}^{2 / 3}\right) K_{c}
$$

The parameter $b$ calculation according to the stated above methodics shows its decrease (intercomponent adhesion level raising) at testing temperature enhancement within the range $b \approx 500-130$.

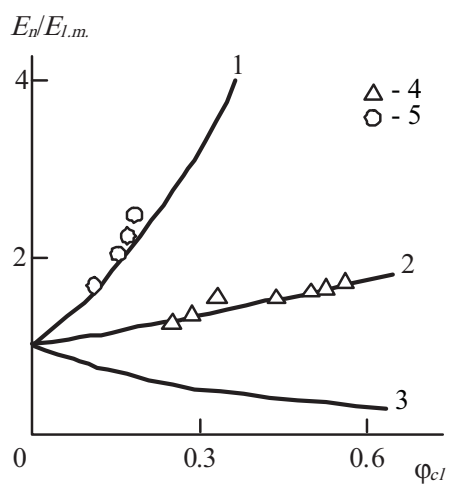

Fig. 1. The dependences of reinforcement degree $E_{p} / E_{l . m \text {. }}$ upon nanoclusters relative fraction $\mathrm{j}_{c r}, 1-3$ - the theoretical dependences corresponding to the equations (1)-(3). 4, 5 the experimental data for $\mathrm{PC}$ in the temperature ranges: 293-363 K (4) and 373-413 K (5)

As it was shown in paper [10], the level of fillerpolymer matrix interactions is determined by sites (nodes) number $N_{u}$ of filler particle surface, which are accessible for interfacial (intercomponent) bonds formation. The value $N_{u}$ is determined by the general fractal relationship [11]:

$$
N_{u} \sim L^{d_{u}}
$$

where $L$ is filler particles size (in our case - nanoclusters), $d_{u}$ is fractal dimension of "nonscreening" or accessible for intercomponent bonds formation of nanoclusters surface. The dimension $d_{u}$ is determined according to the following equation [11]:

$$
d_{u}=\left(d_{\text {surf }}-1\right)+\left(\frac{d-d_{\text {surf }}}{d_{W}}\right)
$$

where $d_{\text {surf }}$ is fractal dimension of nanocluster surface, $d$ is dimension of Euclidean space, in which fractal is considered (it is obvious, in our case $d=3$ ), $d_{w}$ is dimension of random walk on this surface, which is estimated according to Aharony-Stauffer rule [11]: 


$$
d_{w}=d_{\text {surf }}+1
$$

For the dimension $d_{\text {surf }}$ estimation the following methodics was used. At first the nanocluster diameter $D_{c l}$ was calculated according to the equation [12]:

$$
D_{c l}=2\left(\frac{n_{c l} S}{\pi \eta}\right)^{1 / 2}
$$

where $n_{c l}$ is a segments number in one nanocluster, $S$ is cross-section area of PC macromolecule, which is equal to $30.7 \mathrm{E}^{2}$ [13], $\eta$ is the packing coefficient, accepted equal to 0.868 in case of dense packing.

The value $n_{c l}$ was calculated according to a simple equation [3]:

$$
n_{c l}=\frac{F}{2}
$$

where $F$ is nanocluster functionality, which is equal to chains number emerging from it. The values $F$ for PC are accepted according to the data of paper [3].

Then the nanocluster specific surface $S_{u}$ was estimated [14]:

$$
S_{u}=\frac{6}{\rho D_{c l}}
$$

where $\rho$ is nanocluster density, which is equal to 1200 $\mathrm{kg} / \mathrm{m}^{3}$ in case of PC.

And lastly, the dimension $d_{\text {surf }}$ was calculated with the aid of the following equation [2]:

$$
S_{u}=5250\left(\frac{D_{c l}}{2}\right)^{d_{s u r f}-d}
$$

$N_{u}$ calculation according to the relationship (8) can be done for two cases. A nanocluster is simulated as a cylinder with diameter $D_{c l}$ and length $l_{s t}$, where $l_{s t}$ is statistical segment length, consequently in the first case contacting with loosely-packed matrix nanocluster surface is its butt-end and then $L=D_{c l}$ and in the second case - its side surface and then $L=\stackrel{I}{l t}_{s t} . D_{c l}$ value is determined according to the equation (11) and $l_{s t}$ value is calculated as follows [15]:

$$
1_{s t}=1_{0} C_{\infty}
$$

where $l_{0}$ is the main chain skeletal bond length, equal to $1.25 \mathrm{E}$ for PC [16], $C_{\infty}$ is characteristic ration, which is the indicator [17] of polymeric chain statistical flexibility and is determined according to the following relationship [18]:

$$
C_{\infty}=\frac{2 d_{f}}{d(d-1)\left(d-d_{f}\right)}+\frac{4}{3}
$$

where $d_{f}$ is polymer's structure fractal dimension, which is calculated according to the equation [19]:

$$
d_{f}=(d-1)(1+v)
$$

where $v$ is Poisson's ratio, estimated according to the mechanical tests results with the aid of the relationship [20]:

$$
\frac{\sigma_{Y}}{E_{p}}=\frac{1-2 v}{6(1+v)}
$$

where $\sigma_{Y}$ is yield stress.

In Fig. 2 the dependences $b$ are shown on the value $N_{u}$, corresponding to the two cases considered above. As one can see, in both cases for the range 293-363 K, where nanoclusters - loosely-packed matrix interactions are characterized by strong friction, the value $b$ does not depend on $N_{u}$, that was expected. For the range $373-413 \mathrm{~K}$, where between nanoclusters and loosely-packed matrix ideal adhesion is observed, the linear dependences $b\left(N_{u}\right)$ are obtained. However, at using the value $D_{c l}$ as $L b$ reduction or intercomponent adhesion level raising at $N_{u}$ decrease is obtained and at $N_{u}=0$ the value $b$ reaches its minimum $b=0$. In other words, in this case the intercomponent adhesion greatest level is reached at intercomponent couplings formation sites (nodes), that is physically tactless [10]. And on the contrary, at the condition $L=1_{s t} b$ reduction (intercomponent adhesion level raising) at contacts number $N_{u}$ increase between nanoclusters and loosely-packed matrix is observed that is obvious from the physical point of view. Therefore, the data of Fig. 2 indicate unequivocally that intercomponent adhesion is realized over side cylindrical surface of nanocluster and butt-end surfaces do not take part in this effect formation.

Let us consider geometrical aspects of intercomponent interactions in natural nanocomposites. In Fig. 3 the dependences of nanoclusters butt-end $S_{b}$ and cylindrical $S_{c}$ surfaces area on testing temperature $T$ for PC are shown. As one can see, to transition from strong friction up to ideal adhesion at $T=373 \mathrm{~K}$ the following criterion corresponds:

$$
S_{b} \approx S_{c}
$$

Hence, the transition of intercomponent interactions type from the strong friction nanoclusters - loosely-packed matrix to the ideal adhesion between them is defined by nanoclusters geometry: at $S_{b}>S_{c}$ the interactions first type is realized and at $S_{b}<S_{c}-$ the second one. Proceeding from this, it should be expected that intercomponent interactions level is defined by the ratio $S_{b} / S_{c}$. Actually, the shown in Fig. 4 data demonstrate $b$ reduction at the indicated ratio decrease, but at the criterion (19) realization or $S_{b} / S_{c} \approx 1 S_{b} / S_{c}$ decrease does not result to $b$ reduction and at $S_{b} / S_{c}<1$ intercomponent adhesion level remains maximally high and constant.

\section{Conclusions}

Therefore, the present paper results have demonstrated that nanoclusters - loosely-packed matrix 


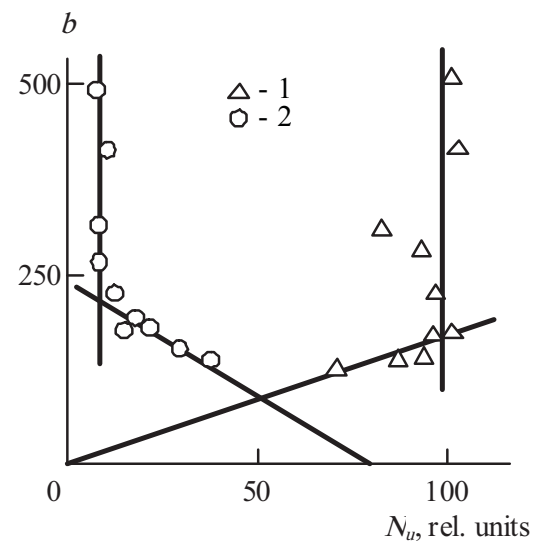

Fig. 2. The dependences of parameter $b$ on number of sites accessible for intercomponent bonds formation $N_{u}$ on nanoclusters surface, calculated at the conditions $L=D_{c l}(1)$ and $L=l_{s t}(2)$ for PC

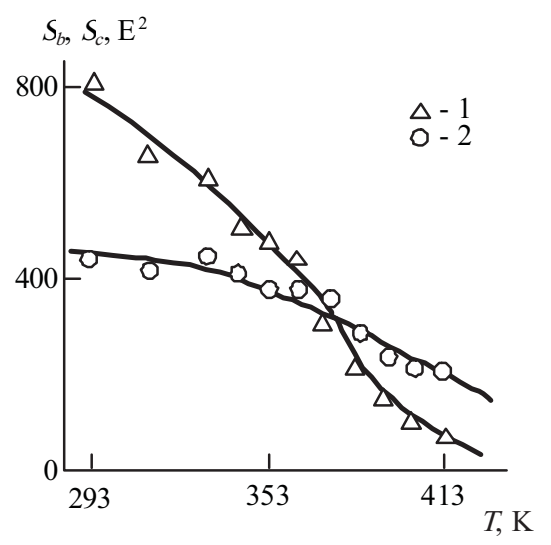

Fig. 3. The dependences of nanoclusters butt-end $S_{b}(1)$ and cylindrical $S_{c}(2)$ surfaces area on testing temperature $T$ for $\mathrm{PC}$

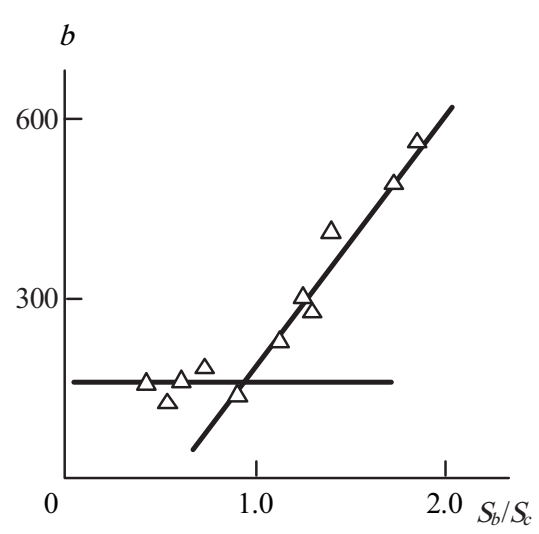

Fig. 4. The dependence of parameter $b$ on nanoclusters butt-end and cylindrical surfaces ratio value $S_{b} / S_{c}$ for PC

adhesion is realized over nanoclusters cylindrical surface. The interactions type (strong friction or ideal adhesion) is defined by nanoclusters butt-end and cylindrical surfaces areas ratio: if the first from the indicated areas is larger than the second one then the strong friction nanoclusters - loosely-packed matrix is realized; if the second area exceeds the first one then between them the ideal adhesion is realized. In the second from the indicated cases intercomponent adhesion level does not depend on the mentioned areas ratio and remains maximally high and constant.

\section{References}

[1] Ivanchev S. and Ozerin A.: Vysokomol. Soed. B, 2006, 48, 1531. [2] Malamatov A., Kozlov G. and Mikitaev M.: Mekhanismy uprochneniya polimernych nanokompozitov. Izd-vo RKhTU Mendeleeva, Moskwa 2006.

[3] Kozlov G. and Zaikov G.: Structure of the polymer amorphous state. Brill Academic Publishers, Utrecht-Boston 2004.

[4] Lipatov Yu.: Mezhfaznye yavleniya v polimerakh. Naukova Dumka, Kiev 1980.

[5] Tugov I. and Shaulov A.: Vysokomol. Soed. B, 1990, 32, 527.

[6] Kozlov G. and Aloev V.: Teoriya perkolyatsii v fiziko-khimii polimerov. Polygraphservis i T., Nal'chik 2005.

[7] Kalinchev E. and Sakovtseva M.: Svoistva i pererabotka termoplastov. Khimiya, Leningrad 1983.

[8] Leidner J. and Woodhams R.: J. Appl. Polymer Sci., 1974, $18,1639$.

[9] Ahmed S. and Jones F.: J. Mater. Sci., 1990, 25, 4933.

[10] Novikov V., Kozlov G. and Bur'yan O.: Mekhanika Kompositnykh Materialov, 2000, 36, 3.

[11] Stanley H.: [in:] Pietronero L. and Tosatti E. (eds.) Fractals in Physics. North-Holland, Amsterdam, Oxford, New York, Tokyo 1986, 463-477.

[12] Kozlov G., Shogenov V. and Mikitaev A.: InzhenernoFizicheskiy Zh., 1998, 71, 1012.

[13] Aharoni S.: Macromolecules, 1985, 18, 2624.

[14] Bobryshev A., Kozomazov V., Babin L. and Solomatov V.: Sinergetika kompozitnykh materialov. NPO ORIUS, Lipetsk 1994.

[15] Wu S.: J. Polymer Sci. B, 1989, 27, 723.

[16] Aharoni S.: Macromolecules, 1983, 19, 1722.

[17] Budtov V.: Fizicheskaya khimiya rastvorov polimerov. Khimiya, Sankt-Peterburg 1992.

[18] Kozlov G. and Novikov V.: Sinergetika i fraktal'nyi analiz schitykh polimerov. Klassika, Moskwa 1998.

[19] Balankin A.: Sinergetika deformiruemogo tela. Izd-vo Ministerstva oborony SSSR, Moskwa 1991.

[20] Kozlov G. and Sanditov D.: Angarmonicheskie efekty i fiziko-mechanicheskie svoistva polimerov. Nauka, Novosibirsk 1994.

\section{ПОЛІМЕРИ ЯК ПРИРОДНІ НАНОКОМПОЗИТИ. 3. ГЕОМЕТРІЯ МІЖКОМПОНЕНТНИХ ВЗАСМОДЙ}

Анотація. Запропоновано оброблення аморфних склоподібних полімерів як природних нанокомпозитів. Показано, щуо геометрія міжкомпонентних взаємодій нанокластер-нещільно упакована матриця визначає адгезію між компонентами природного нанокомпозиту. Оскільки контакт такої матриці здійснюеться на циліндричній поверхні нанокластерів, то чим більша площуа поверхні, тим вища адгезія між компонентами.

Ключові слова: аморфний полімер, нанокомпозит, адгезія, структура, змічнення. 